\title{
Decaffeinated green tea extract rich in epigallocatechin-3-gallate prevents fatty liver disease by increased activities of mitochondrial respiratory chain complexes in diet-induced obesity mice
}

\author{
Aline B. Santamarina ${ }^{a}$, Milena Carvalho-Silva ${ }^{\mathrm{b}}$, Lara M. Gomes ${ }^{\mathrm{b}}$, Marcos H. Okuda ${ }^{\mathrm{a}}$, Aline A. Santana ${ }^{\mathrm{a}}$, \\ Emilio L. Streck ${ }^{\mathrm{b}}$, Marilia Seelaender ${ }^{\mathrm{c}}$, Claudia M. Oller do Nascimento ${ }^{\mathrm{a}}$, Eliane B. Ribeiro ${ }^{\mathrm{a}}$, \\ Fábio S. Lira ${ }^{\mathrm{d}}$, Lila Missae Oyama ${ }^{\mathrm{a}, *}$ \\ ${ }^{a}$ Departamento de Fisiologia, Universidade Federal de São Paulo, São Paulo, SP 04021-001, Brazil \\ b Programa de Pós-Graduação em Ciência da Saúde, Universidade do Extremo Sul Catarinense, Criciúma, SC 88806-000, Brazil \\ ${ }^{c}$ Cancer Metabolism Research Group, Institute of Biomedical Sciences, University of São Paulo, São Paulo, SP 05508-000, Brazil \\ ${ }^{\mathrm{d}}$ Exercise and Immunometabolism Research Group, Department of Physical Education, Universidade Estadual Paulista, Presidente Prudente, SP 19060-900, Brazil
}

Received 19 March 2015; received in revised form 30 June 2015; accepted 6 July 2015

\begin{abstract}
Nonalcoholic fatty liver disease has been considered the hepatic manifestation of obesity. It is unclear whether supplementation with green tea extract rich in epigallocatechin-3-gallate (EGCG) influences the activity of mitochondrial respiratory chain complexes and insulin resistance in the liver. EGCG regulated hepatic mitochondrial respiratory chain complexes and was capable of improving lipid metabolism, attenuating insulin resistance in obese mice. Mice were divided into four groups: control diet+water (CW) or EGCG (CE) and hyperlipidic diet+water (HFW) or EGCG (HFE). All animals received water and diets ad libitum for 16 weeks. Placebo groups received water $(0.1 \mathrm{ml} /$ day $)$ and EGCG groups $(0.1 \mathrm{ml} \mathrm{EGCG} \mathrm{and} 50 \mathrm{mg} / \mathrm{kg} / \mathrm{day})$ by gavage. Cytokines concentrations were obtained by ELISA, protein expression through Western blotting and mitochondrial complex enzymatic activity by colorimetric assay of substrate degradation. HFW increased body weight gain, adiposity index, retroperitoneal and mesenteric adipose tissue relative weight, serum glucose, insulin and Homeostasis Model Assessment of Basal Insulin Resistance (HOMA-IR); glucose intolerance was observed in oral glucose tolerance test (OGTT) as well as ectopic fat liver deposition. HFE group decreased body weight gain, retroperitoneal and mesenteric adipose tissue relative weight, HOMA-IR, insulin levels and liver fat accumulation; increased complexes II-III and IV and malate dehydrogenase activities and improvement in glucose uptake in OGTT and insulin sensitivity by increased protein expression of total AKT, IR $\alpha$ and IRS1. We did not find alterations in inflammatory parameters analyzed. EGCG was able to prevent obesity stimulating the mitochondrial complex chain, increasing energy expenditure, particularly from the oxidation of lipid substrates, thereby contributing to the prevention of hepatic steatosis and improved insulin sensitivity.
\end{abstract}

(c) 2015 Elsevier Inc. All rights reserved.

Keywords: EGCG; NAFLD; Obesity; Mice; Respiratory chain; Insulin resistance

\section{Introduction}

Obesity has grown at an alarming rate over the last decades and is actually considered a public health problem. Genetic and environmental factors are implicated in the development of obesity, with emphasis on unsuitable diets [1]. It is known that the western dietary patterns, particularly the diets high in saturated fat and low in dietary fiber, contribute to the development of several chronic diseases [2-4]. Nonalcoholic fatty liver disease (NAFLD) has become the most common cause of chronic liver illness [5]. The increased incidence of

* Corresponding author. Departamento de Fisiologia, Universidade Federal de São Paulo, Rua Botucatu, 862 Vila Clementino, São Paulo, SP 04023062, Brazil. Tel./fax: +55-11-5576-4765.

E-mail address: Imoyama@gmail.com (L.M. Oyama).
NAFLD is closely related to the increase in obesity, metabolic syndrome and type 2 diabetes mellitus in this populations [6,7].

NAFLD, caused by excessive lipid accumulation in liver, is the hepatic manifestation of insulin resistance and the metabolic syndrome [8,9]. These conditions are caused by an imbalance between triglyceride deposition and synthesis compared with oxidation and secretion by lipoproteins. This initially represents a protective mechanism against the toxicity arising from an increased flux of nonesterified fatty acids (NEFAs) to the liver [10]. The NEFAs can modify hepatic metabolism; one of the effects is to reduce hepatic insulin extraction, contributing to systemic maintenance of hyperinsulinemia $[11,12]$.

Common in obesity is the installation of insulin resistance in visceral adipose tissue. It is well known that adipose tissue insulin resistance has increased lipolysis pathway activity in proportion to the expansion of visceral adipose tissue [13-15]. The activation of this pathway leads to the increase NEFA flows to the liver $[10,16]$. 
In the liver, NEFAs can be oxidized or esterified to form triacylglycerols (TAG). The overload NEFAs that are not used in the oxidative metabolic pathways for production of energy during catabolism (skeletal muscle activity and prolonged fasting) are directed to de novo lipogenesis, responsible for generating TAG and phospholipids from long-chain fatty acids (LCFAs) and glycerol-3-phosphate [11,15,17].

In review, Aubert et al. report that excess LCFAs in the portal circulation are capable of activating cytochrome P450 (CYP450). These data suggest that these lipids can increase hepatic CYP450 expression in NAFLD. In fact, CYP450 induction in NAFLD could be a mechanism of adaptation to lipid overload limit since CYP450-mediated hydroxylation of fatty acids is an alternative route for mitochondrial and peroxisomal oxidation [18].

Mitochondria are the primary cellular organelles for the oxidation and metabolism of fatty acids and glucose. A reduction in mitochondrial function may contribute to the increase in lipid accumulation leading to insulin resistance [10]. These modifications may be related to the reduction in maximal activities of enzyme systems, such as carnitine palmitoyl transferase and mitochondrial respiratory chain complexes, which are responsible for the transport of LCFAs into the organelle and generation of ATP molecules, respectively [19,20]. All of these changes contribute to the exacerbation of fatty liver.

Green tea (Camellia sinensis) is one of the most well-known and oldest beverages, consumed in large quantities all over the world even today. The polyphenols found in green tea have many beneficial metabolic effects [21-23]. The major catechins in green tea are epigallocatechin-3-gallate (EGCG), epicatechin-3-gallate, epigallocatechin and epicatechin, but EGCG is the most abundant catechin and the most biologically active $[24,25]$. Some studies suggest that EGCG has antisteatotic effects on the liver [21,26,27], as well as positive effects on lipid metabolism as described previously $[22,25,28]$.

Currently, it is not clear whether EGCG regulates hepatic mitochondrial respiratory chain complexes able to improve the lipid metabolism and attenuates insulin resistance. Given both the importance of mitochondrial functionality and the beneficial effect of EGCG on pathologic liver conditions, the aim of this study was to demonstrate the effects of EGCG supplementation on the activity of mitochondrial respiratory chain complexes and insulin resistance in mice fed with a high-fat diet (HFD).

\section{Materials and methods}

\subsection{Animal treatment}

All animals were performed according to protocols approved by the Experimental Research Committee of Universidade Federal de São Paulo (CEUA no. 975418). A total of 54 male Swiss mice at 30 days old were used. They were maintained in collective cages in a room with controlled temperature $\left(25 \pm 2^{\circ} \mathrm{C}\right)$, humidity $(60 \pm 5 \%)$ and lighting (12-h light/dark cycle) and received water and diet ad libitum. After 1 week of acclimatization, the mice were divided evenly into four groups: control diet+water (CW), control diet+EGCG (CE), high-fat diet+water (HFW) and high-fat diet+EGCG (HFE). The animals were fed with control diet (AIN-93) [29] or high-fat diet (AIN-93 adapted) during the next 16 weeks (Table 1$)$. The placebo groups received water $(0.1 \mathrm{ml}$ of water by gavage/day) and treatment EGCG ( $0.1 \mathrm{ml} \mathrm{EGCG} \mathrm{and} 50 \mathrm{mg} / \mathrm{kg} /$ day $)$. The animals of placebo groups were weighed once a week, the weight of the EGCG groups was measured every day during the experimental period. We considered as an adiposity index ( $\sum$ WAT) the sum of three adipose depots (mesenteric, epididymal and retroperitoneal) and the relative weight (tissue weight/final weight $\times 100$ ), and delta $(\Delta)$ was calculated (initial weight-final weight). At the end of the experimental period, the mice were euthanized after $12 \mathrm{~h}$ of fasting, and blood and liver were collected. All tissues were weighed and stored at $-80^{\circ} \mathrm{C}$.

\subsection{Serum parameters}

The content of insulin (Millipore, Inc.) and glucose were analyzed by colorimetric method using commercial kits (Labtest). The Homeostasis Model Assessment of Basal Insulin Resistance (HOMA-IR) method of Turner et al. [30] was calculated as the product of fasting insulin (nanograms per milliliter) and fasting glucose (milligrams per deciliter) divided by the constant 22.5 or [HOMA-IR $(\mathrm{mmol} / \mathrm{L})=($ fasting insulin $\times$ fasting glucose)/22.5].
Table 1

Composition of experimental diets, CD and HFD (AIN-93 modified) [29], growth (G) and maintenance $(\mathrm{M})$

\begin{tabular}{lll}
\hline Ingredients & $\mathrm{CD}(\mathrm{G} / \mathrm{M})$ & $\mathrm{HFD}(\mathrm{G} / \mathrm{M})$ \\
\hline Corn starch (\%) & $62.95 / 72.07$ & $40.92 / 40.87$ \\
Casein (\%) & $20.0 / 14.0$ & $13.95 / 14.0$ \\
Soybean oil (\%) & $70.0 / 4.0$ & $7.0 / 4.0$ \\
Lard (\%) & - & $28.08 / 31.2$ \\
Cellulose (\%) & 5 & 5 \\
Mixture of vitamins (\%) & 1.0 & 1.0 \\
Mixture of mineral (\%) & 3.5 & 3.5 \\
L-Cystine (\%) & $0.3 / 0.18$ & $0.18 / 0.18$ \\
Choline bitartrate (\%) & 0.25 & 0.25 \\
Hydroquinone (g/kg) & $0.014 / 0.008$ & $0.014 / 0.008$ \\
Energy (kcal/kg) & $3948 / 3.802$ & $5.352 / 5.362$ \\
\hline
\end{tabular}

\subsection{Oral glucose tolerance test (OGTT)}

Test was performed after 15 weeks of treatment. After $8 \mathrm{~h}$ of fasting, blood was collected from the tail vein to assess basal glucose concentration. Then, a glucose (Merck) solution $(2 \mathrm{~g} / \mathrm{kg})$ was administrated by gavage. Blood samples were collected after 15, 30, $45,60,90$ and 120 min to measure glucose concentration using a glucose analyzer (AccuCheck Roche).

\subsection{Histological analysis}

Sections from right lobe liver were collected immediately after euthanasia, fixed in paraformaldehyde (4\%) for $16 \mathrm{~h}$ and washed with $70 \%$ ethanol overnight. The samples were processed, paraffin embedded and mounted on glass slides. The histological sections of $5 \mu \mathrm{M}$ were stained using hematoxylin and eosin for analysis of the presence of hepatic steatosis.

\subsection{Folch analysis for hepatic TAG content}

To quantify ectopic fat accumulation in the liver, the extraction of the total lipids of the sampled tissues was performed with a solution of chloroform:methanol:water (2:1:0.5). According to the method of Folch et al. [31], the samples were homogenized at $25,000 \mathrm{rpm}$ for $45 \mathrm{~s}$ and centrifuged for $5 \mathrm{~min}$ at $655,1 \mathrm{~g}$. After centrifugation, the organic layer was removed by pipette technique and doubled the total lipid extract evaporated under nitrogen atmosphere. Samples of lipids extract were analyzed for their content of TAG by colorimetric method, using (Labtest) commercial kit.

\subsection{Western blot analysis}

Hepatic tissue were homogenized in lyses buffer containing $100 \mathrm{mM}$ Tris- $\mathrm{HCl}$ ( $\mathrm{pH} 7.5$ ), 1\% Triton X-100, 10\% sodium dodecylsulfate (SDS), 10 mM EDTA, $100 \mathrm{mM}$ sodium fluoride, $10 \mathrm{mM}$ sodium pyrophosphate, $10 \mathrm{mM}$ sodium orthovanadate, $2.0 \mathrm{mM}$ phenylmethylsulfonyl fluoride and $0.1 \mathrm{mg} / \mathrm{ml}$ aprotinin. The homogenate was centrifuged at $14,000 \mathrm{rpm}$ for $45 \mathrm{~min}$ at $4^{\circ} \mathrm{C}$, and the supernatant was collected. The total protein concentration was measured with Bradford Reagent. Proteins in the lysates were electrophoretically separated in $10 \%$ SDS polyacrylamide gel and transferred to nitrocellulose membrane. We used precast gels in 4-15\% Mini-PROTEAN TGX Precast Gels of Bio-Rad Laboratories, Inc., to antibodies of IRS1 and IR.

The membranes were blocked in $1 \%$ bovine serum albumin overnight at room temperature and then incubated overnight with the following primary antibodies: TLR4, IRS1 (insulin receptor substrate 1) and IR $\alpha$ (insulin receptor $\alpha$ ); TNFR-1 (sc-7895), IL-6R (sc-660) and IL-10R $\alpha$ (sc-984) were purchased from Santa Cruz Biotechnology, Inc.(Santa Cruz, CA, USA). The $\beta$-tubulin was obtained from Cell Signaling Technology (Beverly, MA, USA). The membranes were next incubated with horseradish-peroxidase-conjugated secondary antibodies during $1 \mathrm{~h}$ at room temperature. The bands were visualized with enhanced chemiluminescence scanned at UVITec (Cambridge) after adding the ECL reagent (GE Healthcare Bio-Sciences, $A B, U K)$, and the intensities of the bands were quantified in ImageJ software (ImageJ, National Institute of Health, Bethesda, MD, USA).

\subsection{Cytokine concentrations in liver}

The hepatic tissue was homogenized and centrifuged at $14,000 \mathrm{rpm}$ for $45 \mathrm{~min}$ at $4^{\circ} \mathrm{C}$. The supernatant was saved and used in the commercial kits of ELISA (R\&D Systems) to measure the concentrations of TNF- $\alpha$, IL- 6 and IL- 10 following the recommendations of the manufacturer.

\subsection{Enzymatic activity}

2.8.1. Mitochondrial respiratory chain enzymes

The liver were homogenized (1:10, w/v) in SETH buffer (250 mM sucrose, 2 mM EDTA, $10 \mathrm{mM}$ Trizma base and $50 \mathrm{IU} / \mathrm{ml}$ heparin, $\mathrm{pH}$ 7.4). The homogenates were centrifuged at $800 \mathrm{~g}$ for $10 \mathrm{~min}$ and the supernatants were used to determine the activities of the 
mitochondrial respiratory chain enzymes (complexes I, II, II-III and IV). On the day of the assays, the samples were frozen and thawed thrice in hypotonic assay buffer to fully expose the enzymes to substrates and achieve maximal activities. NADH dehydrogenase (complex I) was evaluated according to the method described by Cassina and Radi [32] by the rate of $\mathrm{NADH}$-dependent ferricyanide reduction at $l=420 \mathrm{~nm}$. The activities of succinate-2,6dichloroindophenol (DCIP)-oxidoreductase (complex II) and succinate-cytochrome $c$ oxidoreductase (complex II-III) were determined by the method described by Fischer et al. [33]. Complex II activity was measured by the decrease in absorbance due to the reduction of 2,6-DCIP at $l=600 \mathrm{~nm}$. Complex II-III activity was measured by cytochrome $c$ reduction from succinate at $l=550 \mathrm{~nm}$. The activity of cytochrome $c$ oxidase (complex IV) was assayed according to the method described by Rustin et al. [34], measured by the decrease in absorbance due to the oxidation of previously reduced cytochrome $c$ at $l=550 \mathrm{~nm}$. The activities of the mitochondrial respiratory chain complexes were calculated as nanomoles per minute per milligram of protein.

\subsubsection{Succinate dehydrogenase (SD) activity}

SD activity was determined according to the method of Fischer et al. [33], by following the decrease in absorbance, due to the reduction of 2,6-DCIP at $600 \mathrm{~nm}$, with $700 \mathrm{~nm}$ as a reference wavelength $\left[\varepsilon=19.1 \mathrm{mM}^{-1} \mathrm{~cm}\right.$ to $140 \mathrm{mM}$ potassium phosphate ( $\mathrm{pH} 7.4$ ), $16 \mathrm{mM}$ succinate and $8 \mu \mathrm{M} 2,6-\mathrm{DCIP}]$, and was preincubated with $40-80 \mu \mathrm{g}$ homogenate protein at $30^{\circ} \mathrm{C}$, for $20 \mathrm{~min}$. Subsequently, $4 \mathrm{mM}$ sodium azide, $7 \mu \mathrm{M}$ rotenone and $40 \mu \mathrm{M}$ 2,6-DCIP were added, and the reaction was initiated by the addition of $1 \mathrm{mM}$ phenazinemethasulfate (PMS) and monitored for $5 \mathrm{~min}$, in the presence of PMS.

\subsubsection{Malate dehydrogenase activity}

Aliquots (20 mg protein) were transferred into a medium containing $10 \mathrm{mM}$ rotenone, $0.2 \%$ Triton $\mathrm{X}-100,0.15 \mathrm{mM} \mathrm{NADH}$ and $100 \mathrm{mM}$ potassium phosphate buffer, $\mathrm{pH} 7.4$, at $37^{\circ} \mathrm{C}$. The reaction was started by the addition of $0.33 \mathrm{mM}$ oxaloacetate. Absorbance was monitored as described above.

\subsubsection{Creatine kinase (CK)}

CK activity was measured in liver homogenates pretreated with $0.625 \mathrm{mM}$ lauryl maltoside. The reaction mixture consisted of $60 \mathrm{mM}$ Tris- $\mathrm{HCl}, \mathrm{pH} 7.5$, containing $7 \mathrm{mM}$ phosphocreatine, $9 \mathrm{mM} \mathrm{MgSO}_{4}$ and approximately $0.4-1.2 \mathrm{mg}$ protein in a final volume of $100 \mathrm{ml}$. After $15 \mathrm{~min}$ of preincubation at $37^{\circ} \mathrm{C}$, the reaction was started by the addition of $0.3 \mathrm{mmol}$ of adenosine diphosphate plus $0.08 \mathrm{mmol}$ of reduced glutathione. The reaction was stopped after 10 min by the addition of $1 \mathrm{mmol}$ of $p$-(hydroxymercuri)benzoic acid. The creatine formed was estimated according to the colorimetric method of Hughes [35]. The color was developed by the addition of $100 \mathrm{ml}$ of $2 \%$-naphthol and $100 \mathrm{ml}$ of $0.05 \%$ diacetyl in a final volume of $1 \mathrm{ml}$ and analyzed spectrophotometrically after $20 \mathrm{~min}$ at $540 \mathrm{~nm}$. Results were expressed as nanomoles per minute per milligram protein.

\section{Statistical analyses}

Data were submitted to the quality tests Shapiro-Wilk (normality), Levenne (homogeneity) and/or Mauchly (sphericity). If necessary, data were standardized to $Z$ score. We used corrected values $F$ (Greenhouse-Geisser) in case of nonspherical. The descriptive analysis was performed using the mean \pm standard error. To verify the interactions between groups, we used two-way analysis of variance followed by post hoc test of Bonferroni. The level of significance was $P$ less than or equal to $5 \%$. For statistical analyses, we used the software SPSS version 17.0.

\section{Results}

\subsection{Effect of EGCG treatment and body weight and tissues}

The final weight and the delta $(\Delta)$ weight were significantly higher in the group fed HFW compared with both the $\mathrm{CW}(P=.013 ; P=.008)$ group and the group with $\operatorname{HFE}(P=.011 ; P=.001)$. Less mass gain in the CE group was shown on delta $(\Delta)$ weight $(P=.021)$ when compared to the CW group (Table 2).

The relative weights of liver and epididymal adipose deposits did not differ among the groups. However, the relative weights of mesenteric and retroperitoneal adipose tissues were increased in the group fed HFW when compared with the $\mathrm{CW}(P=.012 ; P=.034)$ and the HFE $(P=.046 ; P=.007)$ groups. In the $\sum$ WAT, we observed increased fat mass in HFW when compared to CW $(P=.01)$ and HFE $(P=.007)$; the supplementation of EGCG significantly suppressed a greater gain of mass in these adipose depots during the experimental period (Table 2).

\subsection{Effect of EGCG treatment on serum parameters and OGTT}

The analyses of serum glucose and insulin levels are shown in Table 3. Serum glucose and insulin levels $(P=.021$ and .001 , respectively) and HOMA-IR $(P=.004)$ showed higher levels in the HFW group when compared to the CW group. Insulin and HOMA-IR showed significantly higher levels in the HFW group versus HFE ( $P=$ .005 and .015 , respectively). The OGTT showed similar results with other insulin resistance biomarkers. The absolute values at baseline and at $30 \mathrm{~min}(P=.020$ and .019 , respectively) were significantly higher in the high-fat group when compared to the CW group; the 30 -min point also showed differences from the HFE $(P=.031)$. When calculating area under the curve (AUC), these differences were reaffirmed between the HFW and CW groups $(P=.001)$ and the HFE group $(P=.003)$ (Fig. 1$)$.

\subsection{Effects of EGCG on ectopic fat accumulation in the liver}

EGCG supplementation (Fig. 2) was able to reduce the accumulation of ectopic fat in the hepatic tissue of the animals fed with high-fat $\operatorname{diet}(P=.007)$.

\subsection{Effect of EGCG treatment in inflammatory profile}

The concentration of cytokines [TNF- $\alpha$, IL-6 and IL-10 (Table 4)] and protein expression of TLR4, TNFR-1, IL-6R and IL-10R $\alpha$ were not different among the groups (Fig. 3D-G).

\subsection{EGCG and modulation of protein expression of insulin pathway}

Protein expression analysis demonstrated that treatment with EGCG improved protein levels of total AKT $(P=.045)$ and IR $\alpha(P=$ .013 ) and revealed a significant increase in the HFE group in comparison with the HFW group. Supplementation with EGCG enhanced the protein expression of IRS1 $(P=.046)$ in the CE group when compared to the CW group (Fig. 3A-C).

\subsection{EGCG in the glycolytic and oxidative metabolism enzymes in liver}

Assessing the activity of the enzymes in the mitochondrial complex in order to observe oxidative metabolism, we observed the increase in the activities of complex I $(P=.001)$ and complex IV $(P=.04)$ in the HFE group versus the HFW group. Complex II did not show change among the experimental groups; however, complexes II-III and IV were increased in the HFW group when compared to $\mathrm{CW}[P=.003$ and .015 , respectively (Fig. 4A-D)]. In the glycolytic metabolic pathway,

Table 2

Body weight, absolute and relative tissue weight

\begin{tabular}{lllll}
\hline Parameters & CW & CE & HFW & HFE \\
\hline Initial weight (g) & $25.9 \pm 1.6$ & $23.2 \pm 0.7$ & $23.5 \pm 1.8$ & $26.1 \pm 1.4$ \\
Final weight (g) & $48.3 \pm 2.4$ & $40.2 \pm 1.7$ & $57.3 \pm 2.7^{* *}$ & $45.5 \pm 2.4^{* * *}$ \\
Delta weight (g) & $23.7 \pm 2.71$ & $17.3 \pm 1.3^{*}$ & $33.8 \pm 2.2^{* *}$ & $19.3 \pm 2.1^{* * *}$ \\
Epididymal (\%) & $4.14 \pm 0.51$ & $4.07 \pm 0.42$ & $5.33 \pm 0.72$ & $4.23 \pm 0.91$ \\
Retroperitoneal (\%) & $1.14 \pm 0.10$ & $1.09 \pm 0.07$ & $1.44 \pm 0.12^{* *}$ & $0.98 \pm 0.05^{* * *}$ \\
Mesenteric (\%) & $1.85 \pm 0.30$ & $1.65 \pm 0.22$ & $3.04 \pm 0.30^{* *}$ & $2.02 \pm 0.52^{* * *}$ \\
EWAT (g) & $3.75 \pm 0.60$ & $2.76 \pm 0.33$ & $5.56 \pm 0.30^{* *}$ & $3.32 \pm 0.56^{* * *}$ \\
Liver (g) & $2.1 \pm 0.16$ & $1.57 \pm 0.08^{*}$ & $2.33 \pm 0.26$ & $1.8 \pm 0.15$ \\
Liver (\%) & $4.13 \pm 0.09$ & $3.93 \pm 0.19$ & $4.01 \pm 0.19$ & $3.96 \pm 0.30$ \\
\hline
\end{tabular}

$* P<.05$, control diet and EGCG (CE) group versus control diet and water (CW) group $(n=14)$.

** $P<.05$, high-fat diet and water (HFW) group versus CW group ( $n=13-14$ ).

*** $P<.05$, high-fat diet and EGCG (HFE) group versus HFW group $(n=13)$. 
Table 3

Serum concentrations of fasting glucose and fasting insulin and homoeostasis model assessment (HOMA-IR) in different experimental groups

\begin{tabular}{lrrrr}
\hline Parameters & \multicolumn{1}{l}{ CW } & \multicolumn{1}{l}{ CE } & \multicolumn{1}{l}{ HFW } & \multicolumn{1}{l}{ HFE } \\
\hline Glucose $(\mathrm{mg} / \mathrm{dl})$ & $135.6 \pm 5.18$ & $128.5 \pm 4.42$ & $168.7 \pm 16.6^{* *}$ & $149.1 \pm 7.1$ \\
Insulin $(\mathrm{ng} / \mathrm{ml})$ & $1.5 \pm 0.18$ & $0.82 \pm 0.13$ & $3.4 \pm 0.64^{* *}$ & $1.52 \pm 0.21^{* * *}$ \\
HOMA-IR & $9.21 \pm 1.25$ & $4.65 \pm 0.77$ & $15.78 \pm 2.32^{* *}$ & $9.91 \pm 1.2^{* * *}$ \\
\hline${ }^{* *} P<.05$, high-fat diet and water (HFW) group versus CW group $(n=13-14)$. \\
${ }^{* * *} P<.05$, high-fat diet and EGCG (HFE) group versus HFW group $(n=13)$.
\end{tabular}

we found an improvement in the activity of malate dehydrogenase $(P=.001)$ in HFW when compared to the CW group; nevertheless, we did not find differences in the activities of CK and SD (Fig. 5A-C).

\section{Discussion}

The major findings of the present study involve the capacity of EGCG to prevent fatty liver in mice fed with HFD. Our data demonstrated that EGCG treatment produced improvements in metabolic profiles and insulin resistance and increased activities of mitochondrial respiratory chain complexes in liver obese mice.

Several studies in humans [36-39] and rodents [8,16,19,40,41] presented strong evidence that HFD, particularly rich in saturated fatty acids, promoted the development of three pathological features associated with the metabolic syndrome: dyslipidemia, insulin resistance/glucose intolerance and increased visceral adiposity [42]. Our experimental model of diet to induce obesity proved to be effective in simulating obesity with treatment of 16 weeks. This finding was clear when we observe value of delta $(\Delta)$ and the adiposity index of mice fed the high-fat diet for 16 weeks (Table 2). Serum parameters also corroborated the effectiveness of the diet in inducing obesity and metabolic syndrome, with higher insulin and fasting blood glucose levels (Table 3 ). The decaffeinated green tea extract rich in EGCG played an obesity protective role and caused a reduction in weight gain and fat deposits (Table 2). It also caused an improvement in measured serum parameters and insulin sensitivity in the groups supplemented with EGCG (Table 3).

There are extensive descriptions in the literature about the role of low-grade inflammation in the development and establishment of obesity [13]. It is important to remember that obesity is a complex and multifactorial disease, and there are several factors that appear to influence its biomarkers such as gender [43], age [44], type of fatty acid offered [45] and duration of therapy [46]. Interestingly, our data showed that high-fat feeding during the 16 -week period did not alter the content of proinflammatory or antiinflammatory cytokines IL-10, IL-6 or TNF- $\alpha$ and respective receptors, nor did it alter the TLR4 protein expression levels in the liver (Table 4 and Fig. 3 ). Some studies have

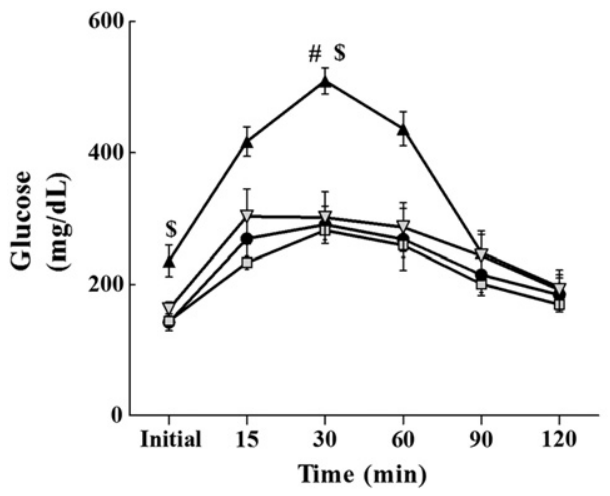

reported dissociation between insulin resistance and inflammation in the liver. In agreement with our results, Turner et al. [47] demonstrated that insulin resistance and steatosis was clearly higher in rats after a few days of a high-fat diet, but even after 16 weeks of high-fat diet, alterations in inflammation in the liver were not detected. Carillon et al. confirmed that insulin resistance and obesity inflammation were disassociated in the liver [48]. They proposed that the inflammatory imbalance in obesity may not always be evident, particularly in the liver, whereas the tissue may exert a strict regulatory role, which could occur after long periods of exposure to a high-fat diet.

There is evidence that green tea catechins such as EGCG have potential as antiobesity tool to its comorbidities. The functions of green tea catechins operate through several different mechanisms, and these mechanisms interact to change the energy balance, the formation of reactive oxygen species and the activities of obesityrelated cells [49]. Focusing on energy balance, EGCG has been shown to be such an effective weapon against obesity by acting on two different levels that together provide a reduction in weight gain. The EGCG on the one hand, in numerous studies, has shown to be a potent activator of AMPK pathway that is renowned for increase energy expenditure and activates lipid oxidation pathways [50]. On the other hand, AMPK also acts on the lipogenesis routes, reducing the activity of enzymes that activate these pathways [51]. Therefore, EGCG is able to increase energy expenditure and at the same time reduce the pathways that make lipid storage in adipose tissue. These two factors together make the effect of EGCG be so evident in obesity.

It has been suggested that ectopic accumulation of liver triglycerides is an important mediator of hepatic insulin resistance. Some groups [6,52] have defended the hypothesis that lipid accumulation in the liver leads to hepatic insulin resistance with evidence of a doseresponse relationship between the content of liver lipids and insulin action. This demonstrated that the prevention of hepatic fat accumulation nullified the development of insulin resistance in the liver. In this study, we observed that their results were similar to ours. The TAG content was reduced under EGCG supplementation, as can be clearly seen in the representative images from histological sections (Fig. 2). The OGTT and HOMA-IR indicated change in insulin responsiveness altered by HFD; in contrast, supplementation with EGCG improved insulin sensitivity and glucose uptake in the HFE group when compared to the HFW group (Fig. 1). This effect might be observed due to an increase in the expression of some proteins in the insulin signaling pathway, such as AKT, IR $\alpha$ and its coactivator substrate IRS1 in total fractions (Fig. 3). This improvement was observed even in mice fed high-fat diets supplemented with EGCG.

The liver plays a crucial role, particularly in lipid metabolism, and is a key organ for the maintenance of systemic homeostasis glucose. Evidence linking mitochondrial dysfunction, insulin resistance and
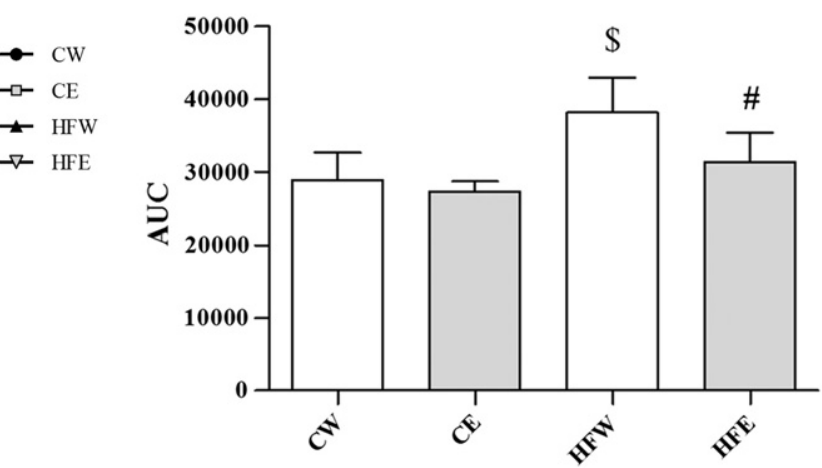

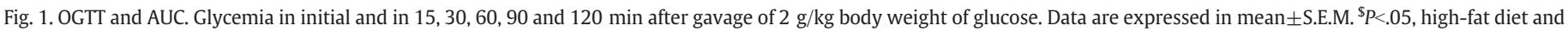
water (HFW) group versus CW group $(n=4-5) .{ }^{*} P<.05$, high-fat diet and EGCG (HFE) group versus HFW group $(n=4-5)$. 

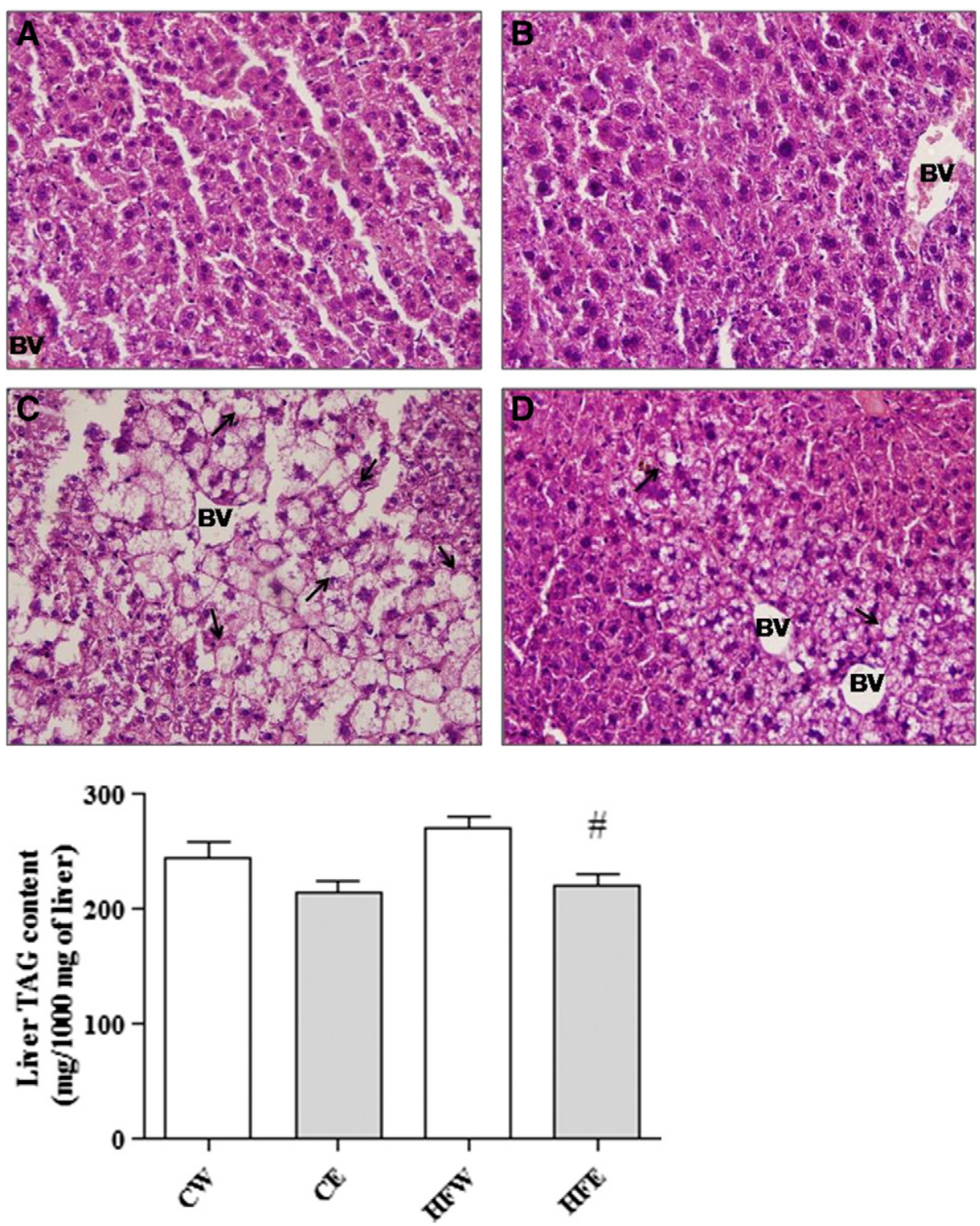

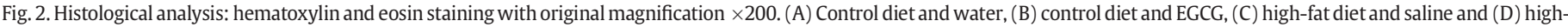

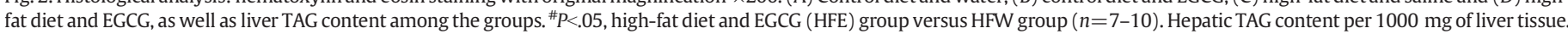

glucose tolerance installation has been suggested [20,53]. The mitochondria have great adaptive potential and can easily adapt to the specific environment and energy demands of the tissue [54]. Holmström postulated that these adaptations in mitochondrial function were a consequence of transcriptional regulation observed in mRNA expression profiles and mitochondrial proteins; they could have been due to excess energy substrate supply and disorders in blood glucose and energy homeostasis of the whole body in obesity and diabetes [20].

Human studies have shown similar results, indicating that the presence of peripheral insulin resistance is associated with reduced gene expression involved in mitochondrial oxidative

Table 4

Liver concentrations of cytokines in different experimental groups

\begin{tabular}{lrcrr}
\hline Parameters & \multicolumn{1}{l}{ CW } & \multicolumn{1}{l}{ CE } & HFW & \multicolumn{1}{l}{ HFE } \\
\hline TNF- $\alpha$ (pg/mg protein) & $5.29 \pm 0.70$ & $6.36 \pm 0.77$ & $5.79 \pm 0.27$ & $5.74 \pm 1.22$ \\
IL-10 (pg/mg protein) & $49.50 \pm 2.37$ & $63.05 \pm 6.26$ & $58.34 \pm 4.81$ & $46.47 \pm 3.14$ \\
IL-6 (pg/mg protein) & $97.7 \pm 7.05$ & $121.93 \pm 12.09$ & $92.86 \pm 7.41$ & $96.65 \pm 8.5$ \\
\hline
\end{tabular}

phosphorylation [55]. In rodents, high-fat diets led to obesity, insulin resistance and hepatic steatosis with concomitant reductions in respiratory capacity and increased oxidative stress in liver mitochondria [56-58]. In our study, we provided evidence that supplementation with EGCG improved mitochondrial respiratory capacity in livers of high-fat-induced obese mice due to an increase in mitochondrial complex IV (Fig. 4).

Complex I is the first step of the respiratory mitochondrial chain and the most common site for mitochondrial abnormalities. Dysfunction in this complex inhibits the mitochondrial electron flow from the Fe-S complex I to the ubiquinone centers and therefore may block the entire process of oxidative phosphorylation. EGCG had the effect of enhancing the activity of this complex and consequently enhancing the electron transport chain $[40,55,59,60]$. Complex II is the second entry point of reducing equivalents into the mitochondrial respiratory chain via FADH, and it is the only complex that pumps protons across the inner mitochondrial membrane. Complex III represents a confluence point for reducing equivalents from various dehydrogenases; it can catalyze the transfer of electrons from hydroxyquinones. This finding 

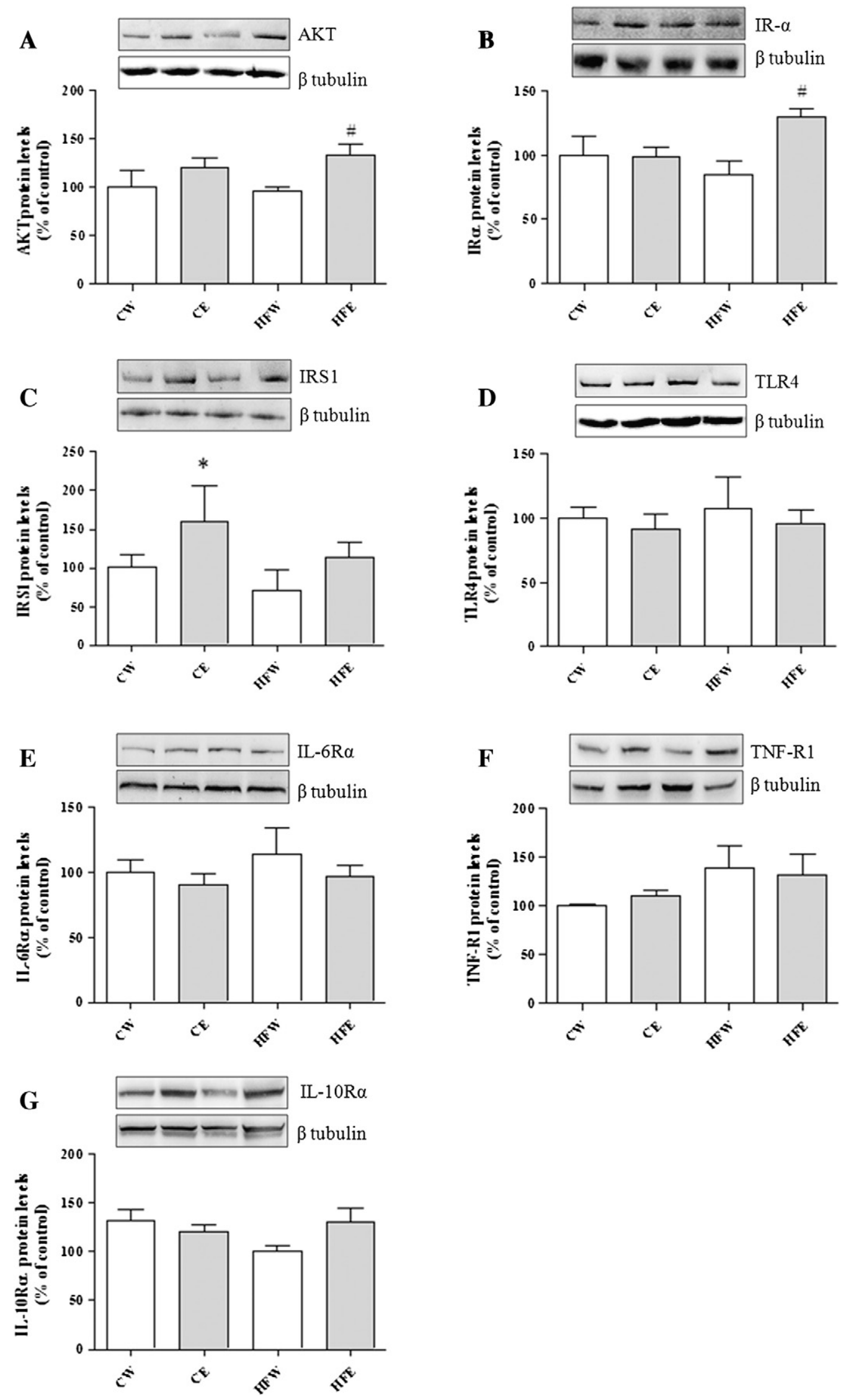

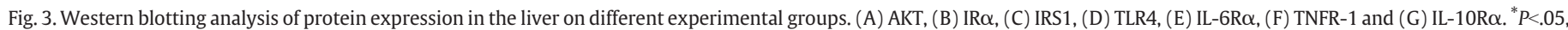
control diet and EGCG (CE) group versus control diet and water (CW) group ( $n=4-7)$. ${ }^{*} P<.05$, high-fat diet and EGCG (HFE) group versus HFW group ( $n=4-7$ ). 
A

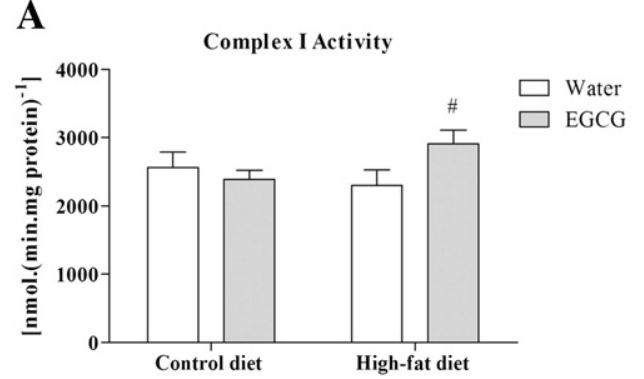

C

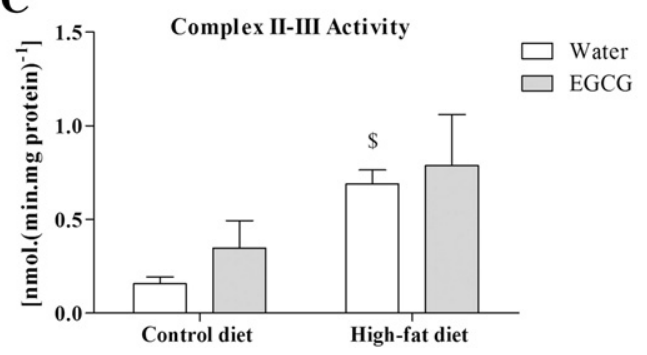

B

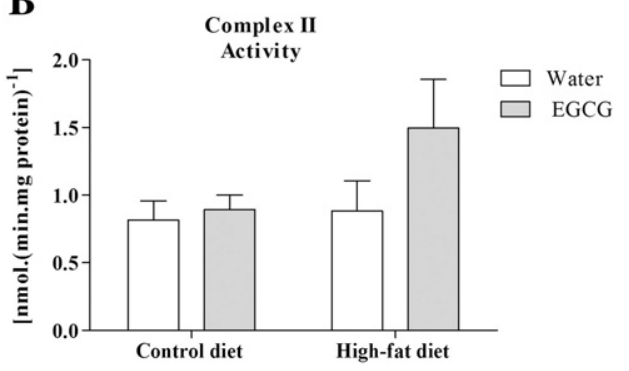

D

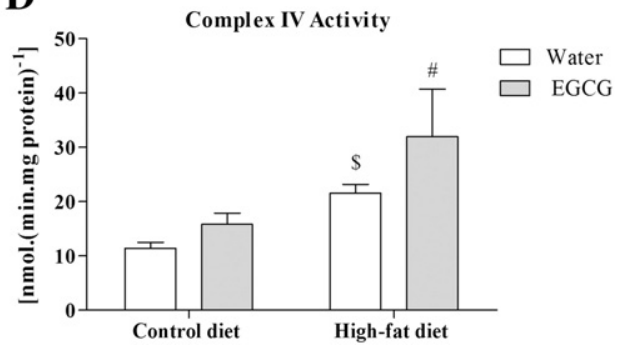

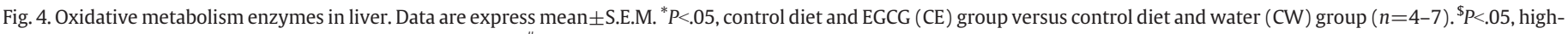
fat diet and water (HFW) group versus CW group $(n=4-7) .{ }^{*} P<.05$, high-fat diet and EGCG (HFE) group versus HFW group ( $\left.n=4-7\right)$.

was in contrast to the striking observation of mitochondrial dysfunction in the liver from the high-fat-induced mice without catechins once there was a significant increase in activity of the II-III complexes in hyperlipidic group [19,61] (Fig. 4).

Complex IV forms part of heme-copper oxygen reductase superfamily that has the ability to catalyze the complete reduction of $\mathrm{O}_{2}$ to water, thus promoting the translocation of protons through the mitochondrial membrane. Complex IV deficiencies can interrupt the process of oxidative phosphorylation, thus decreasing the production of energy for the cells to function properly. Other studies have shown the deleterious effects that the high-fat diet produced in this complex, by reducing the oxidative process $[20,56,57,62]$. In the HFE group, we found an increase in the oxidative process generated by supplementation with EGCG (Fig. 4).

Our research revealed that supplementation with EGCG potentially appeared to increase the activity of the mitochondrial complex chain and thereby increased the oxidation of lipids and prevented the rise of hepatic steatosis. Effect of EGCG appeared to be an increase in the activity of the signaling pathway associated with insulin and glucose uptake.

We concluded that supplementation with decaffeinated green tea extract, which was rich in EGCG, was able to prevent the deleterious effects associated with obesity and ingestion of a high-fat diet. This

\section{A}
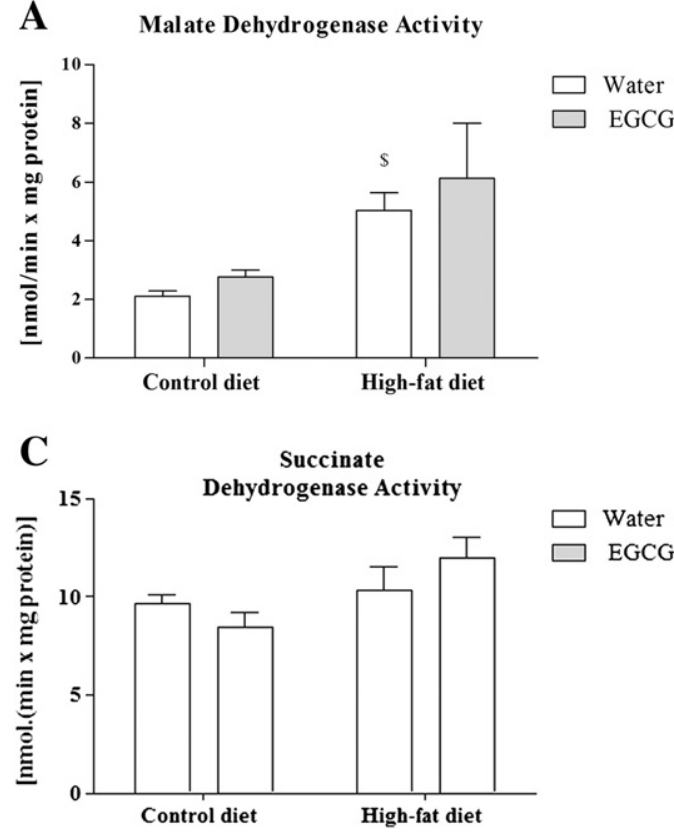

B

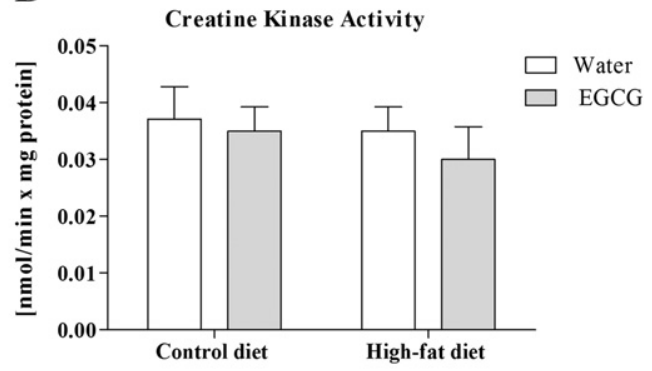


beneficial effect may be due to the effect of stimulation of mitochondrial complex chain and increased energy expenditure, particularly from the oxidation of lipid substrates, thereby contributing to the prevention of hepatic steatosis and improved insulin sensitivity. Results from our study demonstrated that EGCG can be an important tool against obesity.

\section{Potential Conflicts of Interest}

All authors declare no conflicts of interest.

\section{Acknowledgments}

This work was supported by Conselho Nacional de Desenvolvimento Científico e Tecnológico, Fundação de Amparo a Pesquisa do Estado de São Paulo (2014/19508-7) and Coordenação de Aperfeiçoamento de Pessoal de Nível Superior.

\section{References}

[1] Darnton-Hill I, Nishida C, James W. A life course approach to diet, nutrition and the prevention of chronic diseases. Public Health Nutr 2007;7:101-21. http://dx. doi.org/10.1079/PHN2003584.

[2] Delarue J, Magnan C. Free fatty acids and insulin resistance. Curr Opin Clin Nutr Metab Care 2007;10:142-8. http://dx.doi.org/10.1097/MCO.0b013e328042ba90.

[3] Woods SC, Seeley RJ, Rushing PA, D'Alessio D, Tso P. A controlled high-fat diet induces an obese syndrome in rats. J Nutr 2003;133:1081-7.

[4] Mayén A-L, Marques-Vidal P, Paccaud F, Bovet P, Stringhini S. Socioeconomic determinants of dietary patterns in low- and middle-income countries: a systematic review. Am J Clin Nutr 2014. http://dx.doi.org/10.3945/ajcn.114. 089029.

[5] Charlton MR, Burns JM, Pedersen RA, Watt KD, Heimbach JK, Dierkhising RA, et al. Frequency and outcomes of liver transplantation for nonalcoholic steatohepatitis in the United States. Gastroenterology 2011;141:1249-53. http://dx.doi.org/10. 1053/j.gastro.2011.06.061.

[6] Erickson SK. Nonalcoholic fatty liver disease. J Lipid Res 2009;50:S412-6. http:// dx.doi.org/10.1194/jlr.R800089-JLR200.

[7] Masuoka HC, Chalasani N. Nonalcoholic fatty liver disease: an emerging threat to obese and diabetic individuals. Ann N Y Acad Sci 2013;1281:106-22. http://dx. doi.org/10.1111/nyas.12016.

[8] De Wit NJW, Afman LA, Mensink M, Müller M. Phenotyping the effect of diet on non-alcoholic fatty liver disease. J Hepatol 2012;57:1370-3. http://dx.doi.org/10. 1016/j.jhep.2012.07.003.

[9] Gaggini M, Morelli M, Buzzigoli E, DeFronzo RA, Bugianesi E, Gastaldelli A. Nonalcoholic fatty liver disease (NAFLD) and its connection with insulin resistance, dyslipidemia, atherosclerosis and coronary heart disease. Nutrients 2013;5: 1544-60. http://dx.doi.org/10.3390/nu5051544.

[10] Ye J. Mechanisms of insulin resistance in obesity. Front Med 2013;7:14-24. http:// dx.doi.org/10.1007/s11684-013-0262-6.

[11] Byrne CD. Ectopic fat, insulin resistance and non-alcoholic fatty liver disease. Proc Nutr Soc 2013;72:412-9. http://dx.doi.org/10.1017/S0029665113001249.

[12] Vigouroux C, Caron-Debarle M, Le Dour C, Magré J, Capeau J. Molecular mechanisms of human lipodystrophies: from adipocyte lipid droplet to oxidative stress and lipotoxicity. Int J Biochem Cell Biol 2011;43:862-76. http://dx.doi.org/ 10.1016/j.biocel.2011.03.002.

[13] Gregor MF, Hotamisligil GS. Inflammatory mechanisms in obesity. Annu Rev Immunol 2011;29:415-45. http://dx.doi.org/10.1146/annurev-immunol031210-101322.

[14] Ceddia RB. The role of AMP-activated protein kinase in regulating white adipose tissue metabolism. Mol Cell Endocrinol 2013;366:194-203. http://dx.doi.org/10. 1016/j.mce.2012.06.014.

[15] Stanhope KL, Havel PJ. Fructose consumption: potential mechanisms for its effects to increase visceral adiposity and induce dyslipidemia and insulin resistance. Curr Opin Lipidol 2008;19:16-24. http://dx.doi.org/10.1097/MOL.0b013e3282f2b24a.

[16] Shoelson SE, Lee J, Goldfine AB. Inflammation and insulin resistance. J Clin Invest 2006;116:1793-801. http://dx.doi.org/10.1172/JCI29069.

[17] Côté I, Ngo Sock ET, Lévy E, Lavoie J-M. An atherogenic diet decreases liver FXR gene expression and causes severe hepatic steatosis and hepatic cholesterol accumulation: effect of endurance training. Eur J Nutr 2013;52:1523-32. http:// dx.doi.org/10.1007/s00394-012-0459-5.

[18] Aubert J, Begriche K, Knockaert L, Robin MA, Fromenty B. Increased expression of cytochrome P450 2E1 in nonalcoholic fatty liver disease: mechanisms and pathophysiological role. Clin Res Hepatol Gastroenterol 2011;35:630-7. http://dx. doi.org/10.1016/j.clinre.2011.04.015.

[19] Sverdlov AL, Elezaby A, Behring JB, Bachschmid MM, Luptak I, Tu VH, et al. High fat, high sucrose diet causes cardiac mitochondrial dysfunction due in part to oxidative post-translational modification of mitochondrial complex II. J Mol Cell Cardiol 2014. http://dx.doi.org/10.1016/j.yjmcc.2014.07.018.
[20] Holmström MH, Iglesias-Gutierrez E, Zierath JR, Garcia-Roves PM. Tissue-specific control of mitochondrial respiration in obesity-related insulin resistance and diabetes. Am J Physiol Endocrinol Metab 2012;302:E731-9. http://dx.doi.org/10. 1152/ajpendo.00159.2011.

[21] Xiao J, Ho CT, Liong EC, Nanji AA, Leung TM, Lau TYH. Epigallocatechin gallate attenuates fibrosis, oxidative stress, and inflammation in non-alcoholic fatty liver disease rat model through TGF/SMAD, PI3 K/Akt/FoxO1, and NF-kappa B pathways. Eur J Nutr 2014;53:187-99. http://dx.doi.org/10.1007/s00394-013-0516-8.

[22] Cunha CA, Lira FS, Rosa Neto JC, Pimentel GD, Souza GIH, da Silva CMG, et al. Green tea extract supplementation induces the lipolytic pathway, attenuates obesity, and reduces low-grade inflammation in mice fed a high-fat diet. Mediators Inflamm 2013;2013:635470. http://dx.doi.org/10.1155/2013/635470.

[23] Wang S, Moustaid-Moussa N, Chen L, Mo H, Shastri A, Su R, et al. Novel insights of dietary polyphenols and obesity. J Nutr Biochem 2014;25:1-18. http://dx.doi.org/ 10.1016/j.jnutbio.2013.09.001.

[24] Costa S, Utan A, Cervellati R, Speroni E, Guerra MC. Catechins: natural free-radical scavengers against ochratoxin A-induced cell damage in a pig kidney cell line (LLC-PK1). Food Chem Toxicol 2007;45:1910-7. http://dx.doi.org/10.1016/j.fct. 2007.04.008.

[25] Kim H-S, Quon MJ, Kim J-A. New insights into the mechanisms of polyphenols beyond antioxidant properties; lessons from the green tea polyphenol, epigallocatechin 3-gallate. Redox Biol 2014;2:187-95. http://dx.doi.org/10.1016/j.redox. 2013.12.022.

[26] Bose M, Lambert JD, Ju J, Reuhl KR, Shapses SA, Yang CS. The major green tea polyphenol, (-)-epigallocatechin-3-gallate, inhibits obesity, metabolic syndrome, and fatty liver disease in high-fat-fed mice. J Nutr 2008;138:1677-83. http://dx.doi.org/10.1016/j.bbi.2008.05.010.

[27] Banach MS, Dong Q O'Brien PJ. Hepatocyte cytotoxicity induced by hydroperoxide (oxidative stress model) or glyoxal (carbonylation model): prevention by bioactive nut extracts or catechins. Chem Biol Interact 2009;178:324-31. http:// dx.doi.org/10.1016/j.cbi.2008.10.003.

[28] Murase T, Haramizu S, Shimotoyodome A, Nagasawa A, Tokimitsu I. Green tea extract improves endurance capacity and increases muscle lipid oxidation in mice. Am J Physiol Regul Integr Comp Physiol 2005;288:R708-15. http://dx.doi. org/10.1152/ajpregu.00693.2004.

[29] Reeves PG, Nielsen FH, Fahey GC. AIN-93 purified diets for laboratory rodents: final report of the American Institute of Nutrition ad hoc writing committee on the reformulation of the AIN-76A rodent diet. J Nutr 1993;123:1939-51.

[30] Turner RC, Holman RR, Matthews D, Hockaday TD, Peto J. Insulin deficiency and insulin resistance interaction in diabetes: estimation of their relative contribution by feedback analysis from basal plasma insulin and glucose concentrations. Metabolism 1979;28: 1086-96. http://dx.doi.org/10.1016/0026-0495(79)90146-x.

[31] Folch J, Lees M, Sloane Stanley GH. A simple method for the isolation and purification of total lipides from animal tissues. J Biol Chem 1957. http://dx.doi. org/10.1371/journal.pone.0020510.

[32] Cassina A, Radi R. Differential inhibitory action of nitric oxide and peroxynitrite on mitochondrial electron transport. Arch Biochem Biophys 1996;328:309-16. http://dx.doi.org/10.1006/abbi.1996.0178.

[33] Fischer JC, Ruitenbeek W, Berden JA, Trijbels JMF, Veerkamp JH, Stadhouders AM, et al. Differential investigation of the capacity of succinate oxidation in human skeletal muscle. Clin Chim Acta 1985;153:23-36. http://dx.doi.org/10.1016/00098981(85)90135-4.

[34] Rustin P, Bourgeron T, Munnich A, Enfant DI. Endomyocardial biopsies for early detection of mitochondrial disorders in hypertrophic cardiomyopathies. J Pediatr 1994;124:224-8.

[35] Hughes BP. A method for the estimation of serum creatine kinase and its use in comparing creatine kinase and aldolase activity in normal and pathological sera. Clin Chim Acta 1962;7:597-603. http://dx.doi.org/10.1016/00098981(62)90137-7.

[36] An R, Burd NA. Change in daily energy intake associated with pairwise compositional change in carbohydrate, fat and protein intake among US adults, 1999-2010. Public Health Nutr 2014;18:1343-52. http://dx.doi.org/10.1017/ S1368980014001876.

[37] Swinburn BA, Caterson I, Seidell JC, James WP. Diet, nutrition and the prevention of excess weight gain and obesity. Public Health Nutr 2007;7:123-46. http://dx. doi.org/10.1079/PHN2003585

[38] Steyn NP, McHiza Z, Hill J, Davids YD, Venter I, Hinrichsen E, et al. Nutritional contribution of street foods to the diet of people in developing countries: a systematic review. Public Health Nutr 2014;17:1363-74. http://dx.doi.org/10. 1017/S1368980013001158.

[39] Masquio DCL, de Piano A, Campos RMS, Sanches PL, Corgosinho FC, Carnier J, et al. Saturated fatty acid intake can influence increase in plasminogen activator inhibitor-1 in obese adolescents. Horm Metab Res 2014;46:245-51. http://dx.doi. org/10.1055/s-0034-1370908.

[40] Jenkins Y, Sun T-Q, Li Y, Markovtsov V, Uy G, Gross L, et al. Global metabolite profiling of mice with high-fat diet-induced obesity chronically treated with AMPK activators R118 or metformin reveals tissue-selective alterations in metabolic pathways. BMC Res Notes 2014;7:674. http://dx.doi.org/10.1186/ 1756-0500-7-674.

[41] Mullen KL, Pritchard J, Ritchie I, Snook LA, Chabowski A, Bonen A, et al. Adiponectin resistance precedes the accumulation of skeletal muscle lipids and insulin resistance in high-fat-fed rats. Am J Physiol Regul Integr Comp Physiol 2009;296:R243-51. http://dx.doi.org/10.1152/ajpregu.90774.2008.

[42] Axen KV, Dikeakos A, Sclafani A. High dietary fat promotes syndrome X in nonobese rats. J Nutr 2003;133:2244-9. 
[43] El Akoum S, Lamontagne V, Cloutier I, Tanguay J. Nature of fatty acids in high fat diets differentially delineates obesity-linked metabolic syndrome components in male and female C57BL/6J mice. Diabetol Metab Syndr 2011;3:34. http://dx.doi. org/10.1186/1758-5996-3-34.

[44] Korou L-M a, Doulamis IP, Tzanetakou IP, Mikhailidis DP, Perrea DN. The effect of biological age on the metabolic responsiveness of mice fed a high-fat diet. Lab Anim 2013;47:241-4. http://dx.doi.org/10.1177/0023677213480768.

[45] Buettner R, Parhofer KG, Woenckhaus M, Wrede CE, Kunz-Schughart LA, Schölmerich J, et al. Defining high-fat-diet rat models: metabolic and molecular effects of different fat types. J Mol Endocrinol 2006. http://dx.doi.org/10.1677/jme.1.01909.

[46] Ciapaite J, van den Broek NM, Te Brinke H, Nicolay K, Jeneson JA, Houten SM, et al. Differential effects of short- and long-term high-fat diet feeding on hepatic fatty acid metabolism in rats. Biochim Biophys Acta 2011;1811:441-51. http://dx.doi. org/10.1016/j.bbalip.2011.05.005.

[47] Turner N, Kowalski GM, Leslie SJ, Risis S, Yang C, Lee-Young RS, et al. Distinct patterns of tissue-specific lipid accumulation during the induction of insulin resistance in mice by high-fat feeding. Diabetologia 2013;56:1638-48. http://dx. doi.org/10.1007/s00125-013-2913-1.

[48] Carillon J, Romain C, Bardy G, Fouret G, Feillet-Coudray C, Gaillet S, et al. Cafeteria diet induces obesity and insulin resistance associated with oxidative stress but not with inflammation: improvement by dietary supplementation with a melon superoxide dismutase. Free Radic Biol Med 2013;65:254-61. http://dx.doi.org/10. 1016/j.freeradbiomed.2013.06.022.

[49] Moon HS, Lee HG, Choi YJ, Kim TG, Cho CS. Proposed mechanisms of (-)epigallocatechin-3-gallate for anti-obesity. Chem Biol Interact 2007;167:85-98. http://dx.doi.org/10.1016/j.cbi.2007.02.008.

[50] Kanwar J, Taskeen M, Mohammad I, Huo C, Chan TH, Dou QP. Recent advances on tea polyphenols. Front Biosci (Elite Ed) 2012;4:111-31.

[51] Huang CH, Tsai SJ, Wang YJ, Pan MH, Kao JY, Der Way T. EGCG inhibits protein synthesis, lipogenesis, and cell cycle progression through activation of AMPK in p53 positive and negative human hepatoma cells. Mol Nutr Food Res 2009;53: 1156-65. http://dx.doi.org/10.1002/mnfr.200800592.

[52] Morino K, Petersen KF, Shulman GI. Molecular mechanisms of insulin resistance in humans and their potential links with mitochondrial dysfunction. Diabetes 2006; 55. http://dx.doi.org/10.2337/db06-S002.
[53] Lowell BB, Shulman GI. Mitochondrial dysfunction and type 2 diabetes. Science 2005;307:384-7. http://dx.doi.org/10.1126/science.1104343.

[54] Balaban RS. The mitochondrial proteome: a dynamic functional program in tissues and disease states. Environ Mol Mutagen 2010;51:352-9. http://dx.doi.org/10. 1002/em.20574.

[55] Hoeks J, van Herpen N, Mensink M, Moonen-Kornips E, van Beurden D, Hesselink MKC, et al. Mitochondrial dysfunction as consequence rather than cause of human insulin resistance. Diabetes 2010;59:2117-25. http://dx.doi.org/10.2337/db100519.J.H.

[56] Crescenzo R, Bianco F, Falcone I, Prisco M, Liverini G, Iossa S. Alterations in hepatic mitochondrial compartment in a model of obesity and insulin resistance. Obesity (Silver Spring) 2008;16:958-64. http://dx.doi.org/10.1038/oby.2008.10.

[57] Mantena SK, Vaughn DP, Andringa KK, Eccleston HB, King AL, Abrams G, et al. High fat diet induces dysregulation of hepatic oxygen gradients and mitochondrial function in vivo. Biochem J 2009;417:183-93. http://dx.doi.org/10.1042/ BJ20080868.

[58] Iossa S, Lionetti L, Mollica MP, Crescenzo R, Botta M, Barletta A, et al. Effect of highfat feeding on metabolic efficiency and mitochondrial oxidative capacity in adult rats. Br J Nutr 2003;90:953-60. http://dx.doi.org/10.1079/BJN2003000968.

[59] Suthammarak W, Morgan PG, Sedensky MM. Mutations in mitochondrial complex III uniquely affect complex I in Caenorhabditis elegans. J Biol Chem 2010;285: 40724-31. http://dx.doi.org/10.1074/jbc.M110.159608.

[60] Satapati S, Sunny NE, Kucejova B, Fu X, He TT, Méndez-Lucas A, et al. Elevated TCA cycle function in the pathology of diet-induced hepatic insulin resistance and fatty liver. J Lipid Res 2012;53:1080-92. http://dx.doi.org/10.1194/jlr. M023382.

[61] Timmers S, Konings E, Bilet L, Houtkooper RH, van de Weijer T, Goossens GH, et al Calorie restriction-like effects of 30 days of resveratrol supplementation on energy metabolism and metabolic profile in obese humans. Cell Metab 2011;14: 612-22. http://dx.doi.org/10.1016/j.cmet.2011.10.002.

[62] Valdecantos MP, Pérez-Matute P, González-Muniesa P, Prieto-Hontoria PL, Moreno-Aliaga MJ, Martínez JA. Lipoic acid administration prevents nonalcoholic steatosis linked to long-term high-fat feeding by modulating mitochondrial function. J Nutr Biochem 2012;23:1676-84. http://dx.doi.org/10.1016/j.jnutbio. 2011.11.011 